\title{
PENGURUSAN ZAKAT ASNAF MUALAF DI NEGERI JOHOR: SATU SOROTAN
}

\section{Management of Zakah for Mualaf Recipients in the State of Johor: An Overview}

\author{
Othman Sahalan * \\ Luqman Hj Abdullah **
}

\begin{abstract}
The converts are among those who are eligible to receive zakat. The effectiveness of zakat institutions in managing the charity's funds will ensure the objectives of charity that aim to make them steadfast and devoted, and maintain their religious commitment to Islam. In the Malaysian context, the management of the charity is under state charity institutions. This article looks at the management of the charity by the Johore Islamic Council. It reviews the existing problems in the management and also the extent of help that this charity provides to the converts. Jurists debate the rights of the converts, and the programmes implemented by Majlis Agama Islam Johor that are associated with this group are analysed. The findings highlight the areas of improvement needed in the management of the rights of converts. This study is based on qualitative research through the analysis of documents obtained from various sources, including
\end{abstract}

* Pelajar Sarjana, Jabatan Fiqh dan Uusl, Akademi Pengajian Islam, Universiti Malaya,man_328@yahoo.com

** Pensyarah Kanan, Jabatan Fiqh dan Usul, Akademi Pengajian Islam, Universiti Malaya, luqmanabdullah@um.edu.my 
the Ukhuwwah Unit, the Johor Religious Department and interviews with officials. The study revealed that substantial allocations are devoted to the development of these recipients. What can be concluded is that the role of the Johor Islamic Religious Council and all parties of authority in managing the conversion in Johor must be strengthened in order to achieve the main objective of distribution of alms to the converts, which is "ta'līf al-qulüb".

Keywords: Zakat, Mualaf, Management, Majlis Agama Islam Johor (MAIJ)

\section{PENDAHULUAN}

Golongan mualaf adalah antara lapan asnaf yang layak menerima zakat sebagaimana dirakamkan di dalam ayat 60 Surah alTawbah. Tujuan pengagihan zakat kepada golongan ini ialah untuk menjinakkan hati mereka dengan agama Islam yang dengan itu akan menambahkan keyakinan dan komitmen mereka kepada agama. Objektif ini adalah sangat jelas dengan tabiat orang yang baru menerima yang sudah tentu akan terdedah kepada kelemahan iman dan mudah terpengaruh dengan anasir agama asal mereka.

Majlis Agama Islam Johor (MAIJ) telah menyusun skim-skim bantuan mualaf bagi membantu asnaf mualaf di Negeri Johor. Antaranya ialah Skim Bantuan Sara Hidup Bulanan. Skim ini diwujudkan bagi memberikan bantuan kewangan secara bulanan kepada mualaf. Meskipun program skim bantuan ini telah dirancang dengan baik dan dilaksanakan, tetapi penilaian terhadap perlaksanaan tersebut perlu dilakukan untuk mengetahui tahap keberkesanan agihan itu. Oleh itu, satu kajian perlu dilakukan untuk mencari jalan penyelesaian bagi memperkasa institusi zakat untuk mengagih zakat dengan lebih berkesan berdasarkan kepada hasil dapatan kajian yang akan dicadangkan. 


\title{
KONSEP MUALAF DALAM ISLAM
}

Asnaf mualaf merupakan asnaf keempat yang berhak menerima zakat yang disebutkan sebagai al-Mu'allafah Qulübuhum oleh Allah di dalam firmanNya dalam Surah al-Tawbah ayat ke 60:

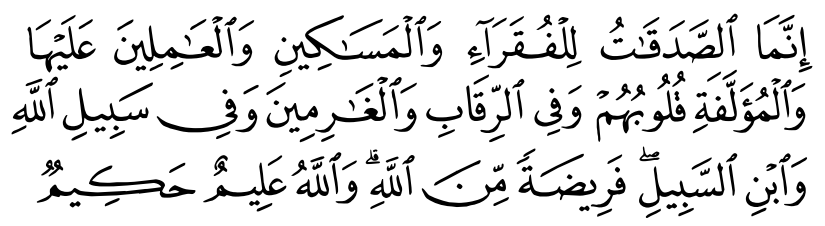

\begin{abstract}
Maksudnya: Sesungguhnya sedekah-sedekah (zakat) itu hanyalah untuk orang-orang fakir, dan orangorang miskin, dan amil-amil yang mengurusnya, dan orang-orang mualaf yang dijinakkan hatinya, dan untuk hamba-hamba yang hendak memerdekakan dirinya, dan orangorang yang berhutang, dan untuk (dibelanjakan pada) jalan Allah, dan orangorang musafir (yang keputusan) dalam perjalanan. (Ketetapan hukum yang demikian itu ialah) sebagai satu ketetapan (yang datangnya) dari Allah. Dan (ingatlah) Allah Maha Mengetahui, lagi Maha Bijaksana.
\end{abstract}

Perkataan mualaf berasal daripada bahasa Arab yang berasal dari allafa - yu'allifu - ta'lïf, yang membawa maksud jinak. Ianya hanya disebutkan sekali sahaja di dalam al-Quran iaitu di dalam ayat asnaf (penerima) zakat. ${ }^{1}$ Dari sudut syarak pula, menurut alZuhaylī, mualaf itu ialah segolongan kafir yang diharapkan hati mereka cenderung kepada Islam dengan pemberian harta dan diharapkan kebaikan mereka, atau menampan kejahatan mereka, atau segolongan orang-orang Islam yang niat mereka masih lemah maka diberikan zakat agar dikuatkan keislaman dan keteguhan iman mereka. ${ }^{2}$ Menurut Kamus Dewan Edisi Keempat, mualaf

\footnotetext{
1 Khālid 'Abd al-Razzāq al-'Ān̄̄, Mașārif al-Zakāt wa Tamlīkuhā fì Daw'i al-Kitāb wa al-Sunnah ('Ammān: Dār Usāmah li al-Nasyr wa al-Tawzī’, 1999), 240.

2 Wahbah al-Zuhaylī, al-Fiqh al-Islāmı̄ wa Adillatuhu (Bayrūt: Dār al-Fikr, c. 4, 2004), $3: 1954$.
} 
(dengan II) bermaksud orang yang baru memeluk agama Islam, ${ }^{3}$ saudara baru. Bagi Abdullah Yusuf Ali, ${ }^{4}$ mualaf itu ialah:

those whose hearts have been (recently) reconciled (to Truth).

Manakala menurut Mohammed Marmaduke Pickthall, ${ }^{5}$ takrifan mualaf merujuk kepada:

"those whose hearts are to be reconciled"

Menurut Ibn Jarīr al-Ṭabarī, mualaf itu ialah satu kaum yang dijinakkan kepada Islam, yang asalnya tidak boleh diberi zakat dan pertolongan, sebagai cara untuk mendapatkan kebaikan mereka dan ahli keluarga atau pengikut mereka seperti Abū Sufyān Bin Harb, 'Uyaynah bin Badr, al-Aqra' bin Habis dan golongan yang setaraf dengan mereka daripada ketua-ketua qabilah. ${ }^{6}$ Kemudian beliau menambah: ...para ahli ta'wil juga berpendapat seperti kami. Beliau juga meriwayatkan satu hadis dengan sanadnya sehingga Ibn 'Abbās: ...dan muallafatu qulübuhum adalah satu kaum yang mendatangi Rasulullah SAW dan telah memeluk Islam. Rasulullah SAW pernah memberikan mereka sebahagian daripada sedekah dan apabila mereka diberikan sedekah maka mereka akan menyatakan: ...ini adalah agama yang baik! Akan tetapi apabila mereka tidak diberi maka mereka akan mencerca dan meninggalkan baginda. Ini adalah bertepatan dengan firman Allah SWT:

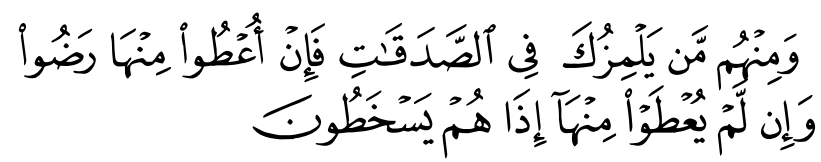

3 Noresah Baharom, Kamus Dewan Edisi Keempat (Dewan Bahasa dan Pustaka, Kuala Lumpur 2007),1046.

4 The Absolute Reality, http://www.quran4u.com/Tafsiraya/009\%20 Tawbah.htm\#ص., diakses pada 21 April 2014.

5 The Islamic Computing Centre, London, http://www.islam101. com/quran/quranPickthal/trans-pickthal.text, diakses pada 21 April 2014.

6 Abū Ja'far Muhammad Ibn Jarīr al-Ṭabarī, al-Tafsìr al-Ṭabarī (Bayrūt: Dār al-Kutub al-'Ilmiyyah, c. 2, 1997), $6: 398$ 
Maksudnya: Dan di antara mereka ada Yang mencelamu (Wahai Muhammad) mengenai (pembahagian) sedekah-sedekah (zakat); oleh itujika mereka diberikan sebahagian daripadanya (menurut kehendak mereka), mereka suka (dan memandangnya adil); dan jika mereka tidak diberikan dari zakat itu (menurut kehendaknya), (maka) dengan serta merta mereka marah.

Manakala di dalam Tafsìr al-Qurțubī, mualaf diertikan sebagai satu kaum pada zaman permulaan Islam yang menzahirkan keislaman mereka, dijinakkan dengan pemberian sebahagian daripada zakat kepada mereka disebabkan keyakinan mereka yang masih lemah terhadap Islam. ${ }^{7}$

Bagi setiap mazhab fiqh, pengertian mualaf itu juga berbeza antara satu dengan yang lain, perbezaan ta'wil pada nas menyebabkan mereka berbeza pendapat. Walau bagaimanapun, perbezaan ini memberi faedah dan manfaat yang besar bersesuaian dengan masa dan ketika.

Imam Syafii di dalam al-Umm ${ }^{8}$ menyatakan bahawa yang dimaksudkan dengan mualaf itu ialah orang yang telah masuk Islam, dan tidak diberikan zakat kepada seorang musyrik untuk menjinakkannya kepada Islam. Sekiranya ada yang menyatakan: Nabi telah memberikan zakat kepada sebahagian orang musyrikin pada hari peperangan Hunain, pemberian itu adalah daripada harta fay', dan daripada harta baginda sendiri, bukan daripada harta zakat, dan hukumnya harus untuk memberi sesuatu daripada harta baginda sendiri.

Para ulama Mazhab Maliki juga membahaskan takrifan mualaf di dalam kitab-kitab mereka. Al-Dusūqī di dalam Hāasyiahnya ${ }^{9}$

7 Abū 'Abd Allāh Muḥammad bin Aḥmad al-Anșārī al-Qurțubī, alJāmi 'li Ahkām al-Qur'ān (Riyāḍ: Maṭba'ah Dār 'Ālam li al-Kutub li al-Ṭibā'ah wa al-Nasyr wa al-Tawzī', 2003), 8 : 178

8 Abu 'Abd Allāh, Muḥammad Bin Idrīs al-Syafi'ī, al-Umm (alManșūrah: Mesir, Dār al-Wafā', 2001), 3 : 183.

9 Syams al-Dīn al-Syaykh Muhammad 'Ārafah al-Dusūqī, Hāsyiah al-Dusūqī 'alā al-Syarh al-Kabīr (Qāhirah: Dār Iḥyā' al-Kutub al'Arabiyyah 'Īsā al-Bābi al-Ḥalabī, t. t), 1 : 495. 
menyatakan muallafun qalbuhu iaitu orang kafir yang diberikan sebahagian daripada zakat supaya ia masuk Islam, ada juga yang menyatakan, mualaf ialah Muslim yang baru memeluk Islam supaya teguh keIslamannya.

Di dalam mazhab Hanbali, takrifan mualaf diluaskan iaitu mualaf ialah ketua yang ditaati dalam kalangan kerabatnya yang diharapkan masuk Islam atau orang yang ditakuti kejahatannya, atau yang diharap kuat imannya atau akan masuk Islam orangorang yang setaraf dengannya daripada golongan kafir.

Manakala di dalam Mazhab Hanafi pula, menurut Imām alKāsān̄̄, mualaf itu ialah pemimpin-pemimpin dan pembesar Arab seperti Abū Sufian, mereka yang berpengaruh dan mempunyai ramai pengikut. Sebahagian mereka memeluk Islam dengan sebenar-benarnya dan sebahagian mereka memeluk Islam secara zahir sahaja dan inilah dia orang-orang munafik. Sebahagian mereka terdiri daripada orang-orang Islam sendiri dan Rasulullah memberi mereka zakat sebagai memujuk hati-hati mereka, dan menetapkan pendirian mereka terhadap Islam, juga sebagai ajakan kepada pengikut-pengikut mereka. Ianya juga sebagai menjinakkan hati mereka yang belum elok Islamnya. ${ }^{10}$

Hasanah Khafidz ${ }^{11}$ menyatakan bahawa tafsiran mualaf yang paling sesuai dengan realiti sekarang ialah "orang yang ingin dilembutkan hatinya supaya cenderung pada Islam dan kuat imannya sama ada terdiri daripada orang yang baru memeluk agama Islam ataupun orang kafir".

Setelah melihat kepada beberapa takrifan tersebut, satu kesimpulan yang boleh diambil ialah bahawa mualaf dalam konteks Malaysia merujuk kepada saudara baru atau saudara kita iaitu orang yang baru memeluk Islam. Pengkaji juga cenderung menyatakan bahawa takrifan yang sesuai untuk al-muallafatu quiūbuhum ialah setiap mereka yang diharapkan daripada pemberian itu untuk membantu Islam, sama ada mengukuhkan

10 Al-Kāsānī 'Alā' al-Dīn Abū Bakar, Badā'i ‘ al-Șanā'i ‘ (Bayrūt: Dār al-Kutub al-'Ilmiyyah,. c. 2, 2003), 2467.

11 Hasanah Abd Khafidz, "Asnaf Lapan: Kesan Nilai Semasa dan Setempat dalam Menentukan Pentafsirannya di Malaysia" (Thesis (Ph.D.), Jabatan Fiqh dan Usul, Akademi Pengajian Islam, Universiti Malaya, 2006). 
Islam di dalam hati mereka, atau menampan kejahatan daripada mereka terhadap orang Islam. Golongan ini adalah terdiri daripada mereka yang belum memeluk Islam dan diharapkan memeluk Islam dengan pemberian ini. Mereka yang baru masuk Islam juga boleh dimasukkan di dalam takrif mualaf yang mana mereka ini diancam oleh musuh-musuh Islam. Maka proses menjinakkan hati mereka adalah salah satu cara untuk memantapkan keislaman mereka dan Islam itu sendiri. ${ }^{12}$

\section{PERBAHASAN ULAMA TENTANG ASNAF MUALAF}

Menurut al-Qaraḍāwī, mualaf itu terbahagi kepada dua bahagian iaitu mualaf dari golongan kafir dan mualaf dari golongan umat Islam sendiri.

a. Mualaf dari golongan kafir pula terbahagi kepada dua kumpulan iaitu;

1. Orang yang diharapkan keIslamannya maka diberikan zakat bagi menguatkan niatnya untuk menerima Islam dan cenderung memeluk Islam. Sebagai contoh, Nabi SAW telah memberikan satu kumpulan daripada orang kafir yang diharapkan jinaknya hati mereka untuk masuk Islam sebagaimana disebutkan di dalam Sahīh Muslim bahawa Nabi SAW telah memberikan kepada Șafwān bin Umaiyah sebahagian daripada ghanimah perang Hunain dan pada ketika itu Șafwān masih lagi kafir.

2. Orang yang ditakuti akan kejahatannya maka adalah diharapkan dengan pemberian ini dia akan menahan diri dari membuat kejahatan begitu juga sekutunya. Diriwayatkan daripada Ibn 'Abbās bahawasanya ada satu kaum yang datang kepada Nabi SAW, yang apabila Nabi memberikan sesuatu kepada mereka, mereka memuji Islam dan apabila Nabi enggan memberikan sesuatu mereka mengeji dan mengaibkan Islam. Perkara ini dirakamkan oleh Allah SWT di dalam Surah al-Tawbah ayat ke-58:

12 Al-Qaradaghi, Prof. Dr. Muhyiddin al-Qaradagh, http:// www.qaradaghi.com/portal/index.php?option $=$ com content\&view=article \&id=256:-q-q-\&catid=30:2009-06-25-09-1959\&Itemid=34, diakses pada 27 April 2014. 


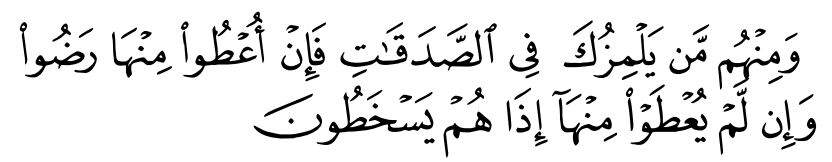

Maksudnya: Dan di antara mereka ada yang mencelamu (wahai Muhammad) mengenai (pembahagian) sedekah-sedekah (zakat); oleh itujika mereka diberikan sebahagian daripadanya (menurut kehendak mereka), mereka suka (dan memandangnya adil); dan jika mereka tidak diberikan dari zakat itu (menurut kehendaknya), (maka) dengan serta merta mereka marah.

Para ulama telah berselisih pendapat pada pemberian zakat bagi kedua-dua kumpulan ini. Bagi Hanabilah dan Malikiyyah, mereka boleh diberikan zakat sebagai galakan (targhīb) untuk masuk Islam, kerana Nabi SAW telah memberikan zakat kepada mualaf daripada kumpulan muslimin dan kafirin. Manakala bagi Ḥanafiyyah dan Syāfi'iyyah, mereka tidak boleh diberikan zakat sama ada bertujuan untuk menjinakkan hati mereka atau tujuan yang lain. Pemberian Nabi SAW pada permulaan Islam adalah kerana pada ketika itu umat Islam masih lagi belum ramai manakala bilangan musuh Islam cukup banyak. Setelah berlalu beberapa masa, dan Allah SWT telah memuliakan Islam dan penganutnya serta tidak berhajat lagi untuk menjinakkan orang-orang kafir. Para Khulafā' al-Rāsyidīn juga tidak memberikan bahagian zakat kepada mereka.

b. Manakala mualaf dari golongan Islam pula terdiri daripada beberapa kumpulan, iaitu:

1. Mereka yang baru memeluk Islam. Tujuan pemberian zakat adalah untuk memperkukuhkan keIslaman mereka.

2. Para pembesar dan pemimpin Islam yang kedudukannya setara dengan kedudukan para pembesar dan pemimpin bukan Islam.

3. Para pemimpin umat Islam yang lemah iman tetapi dihormati di kalangan pengikut mereka.

4. Mereka yang berada di perbatasan negara mengawal keselamatan. 
5. Para pengumpul zakat daripada kumpulan orang Islam yang menentang usaha ini kecuali dilakukan oleh orang-orang yang kuat dan berpengaruh.

\section{KEDUDUKAN MUALAF SELEPAS KEWAFATAN NABI SAW}

Para ulama juga berselisih pendapat dalam permasalahan kekalnya bahagian mereka selepas kewafatan Nabi SAW. Menurut pendapat Hanafiyyah dan Mālikiyyah, bahagian mereka telah gugur dengan berkembangnya Islam, kerana Allah SWT telah memuliakan Islam, dan telah menjadikan Islam terkaya dan tidak berhajat kepada mereka. Maka dengan ini jadilah asnaf zakat itu tujuh sahaja dan bukan lapan. Ini adalah ijmak para sahabat. Imam Malik berkata lagi "tiada hajat lagi untuk dijinakkan hati kerana sekarang Islam telahpun kuat".

Menurut Jumhur ulama termasuklah Khalil daripada Mazhab Maliki, hukum mualaf itu kekal dan tidak dimansuhkan, ${ }^{13}$ justeru diberikan bahagian itu kepada mereka ketika ada keperluan. Perbuatan Saydina 'Umar, 'Uthmān dan 'Alī yang tidak memberikan zakat kepada mereka adalah kerana tiada keperluan untuk diberikan pada zaman pemerintahan mereka, ini kerana mungkin pada ketika itu kemakmuran dan kekayaan dapat dikongsi dengan sama rata di antara seluruh umat Islam. Bukanlah bermakna bahawa bahagian ini digugurkan sama sekali.

Dalam hal ini, benarlah apa yang dikatakan oleh Ibn 'Arabī: ${ }^{14}$ "menurut pandangan saya jika Islam kuat maka hilanglah (hak mereka untuk menerima zakat) dan jika mereka (orang kafir) diperlukan maka hendaklah diberikan peruntukan zakat untuk mereka sebagaimana Rasulullah SAW memberikannya kepada mereka" Dalam sebuah hadis yang sahih ada menyebutkan:

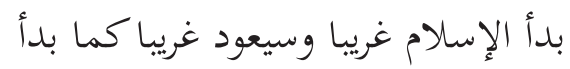

13 Khālid 'Abd Razzāq al-'An̄̄, Mașārif al-Zakāt wa Taml̄̄kuhā fì Daw'ī al-Kitāb wa al-Sunnah ('Ammān: Dār Usāmah li al-Nasyr wa al-Tawzī', 1999), 251.

14 Abū 'Umar al-Namrī al-Qurțubī, al-Jāmi' li Ahkām al-Qur'ān (Qāhirah: Dār al-Ḥadīth, 2002), 4 : 509. 
Maksudnya: "Islam mula dalam keadaan dagang dan akan kembali dagang sebagaimana ia bermula." 15

\section{KONSEP MUALAF DALAM UNDANG-UNDANG PENTADBIRAN ISLAM DI MALAYSIA DAN NEGERI JOHOR}

Setiap negeri di Malaysia mempunyai takrifan tersendiri bagi mualaf. Jika diteliti, semua takrifan ini membawa maksud yang hampir sama dan kebanyakan takrif merujuk mualaf itu sebagai mereka yang baru memeluk Islam dan masih lemah imannya. Namun begitu, terdapat beberapa negeri yang secara jelas mengklasifikasikan mualaf itu kepada dua bahagian iaitu orang kafir dan orang yang baru memeluk Islam. Berikut adalah takrifan mualaf bagi empat negeri di Malaysia menurut Majlis Agama Islam Negeri (MAIN) sebagai contoh:

\begin{tabular}{|c|c|}
\hline Negeri & Takrif Mualaf \\
\hline 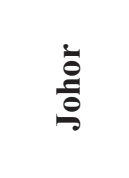 & $\begin{array}{l}\text { "Mereka yang hatinya baru berjinak-jinak dengan } \\
\text { agama Islam dan mendapat hidayah menganuti Islam } \\
\text { supaya mereka merasakan adanya tempat bergantung } \\
\text { bagi menghadapi cabaran yang mendatang". }\end{array}$ \\
\hline 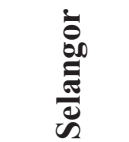 & $\begin{array}{l}\text { Orang yang baru memeluk Islam iaitu "orang yang } \\
\text { dijinakkan hatinya" dengan diberi bantuan supaya } \\
\text { mereka teguh mencintai Islam. }\end{array}$ \\
\hline 离 & $\begin{array}{l}\text { Orang kafir yang ada harapan masuk Islam dan orang } \\
\text { yang baru masuk Islam yang imannya masih lemah. }\end{array}$ \\
\hline
\end{tabular}

15 Abū al-Ḥusayn Muslim bin al-Ḥajjāj al-Qusyayrī al-Naysābūrī, Șahīh Muslim, al-Musamma al-Musnad al-Ṣahīh al-Mukhtașar min al-Sunan bi Naql al- 'Adl 'an al- 'Adl ilä Rasūl Allah SAW, Kitāb alImān (Riyāị: Dār Ṭibah, 2006), no. hadis: 145, 1 : 77. 


\begin{tabular}{|l|l|}
\hline & $\begin{array}{l}\text { Orang yang baru memeluk Islam dan keimanannya } \\
\text { belum lagi kukuh. Mereka ini perlu dijinakkan hatinya } \\
\text { ataupun seseorang yang diharapkan kecenderungan } \\
\text { hatinya untuk menerima Islam. } \\
\text { Nota: Mereka yang telah bertahun-tahun memeluk Islam } \\
\text { terkeluar daripada asnaf mualaf. }\end{array}$ \\
\hline
\end{tabular}

Merujuk kepada beberapa takrifan mualaf di atas, didapati bahawa hanya Sarawak dan Pulau Pinang sahaja yang memasukkan orang bukan Islam di dalam pentakrifan mereka. Manakala negeri-negeri yang lain iaitu Selangor dan Johor sendiri tidak memasukkan orang bukan Islam dalam pentakrifan asnaf mualaf. Namun begitu, menurut sumber daripada Unit Ukhuwwah, Bahagian Dakwah Jabatan Agama Johor selaku pihak yang dipertanggungjawabkan mengurus mualaf di Johor, walaupun tiada peruntukan khas yang disediakan untuk pemberian kepada orang bukan Islam, namun begitu melalui program-program yang disusun di perkampungan orang Asli, pihak Unit Ukhuwwah turut memberi saguhati berbentuk makanan dan sebagainya kepada ketua keluarga dan Tok Batin yang belum Islam sebagai salah satu cara memikat mereka untuk menerima Islam. ${ }^{16}$

Satu perkara yang dibangkitkan berhubung isu ini ialah hukum memberi zakat kepada orang bukan islam bagi tujuan dakwah. ${ }^{17}$ Persoalan mengenai perkara ini juga telah ditimbulkan dalam Muzakarah Jawatankuasa Fatwa Majlis Kebangsaan Bagi Hal Ehwal Islam yang bersidang pada 6-8 September 2007. Muzakarah membincangkan isu ini untuk mendapatkan satu keputusan atau dasar tentang hukum memberikan wang zakat kepada orang bukan Islam bagi tujuan dakwah di bawah asnaf al-Muallafatu Qulübuhum. Muzakarah telah memutuskan bahawa pengagihan zakat perlu diberi keutamaan kepada umat Islam mengikut asnafasnaf yang telah ditetapkan. Walau bagaimanapun, pemerintah

\footnotetext{
16 Temubual bersama Ustazah Maimunah bt Othman, Penolong Pengarah (Ketua) Unit Ukhuwwah, Bahagian Dakwah JAJ, 5 Januari 2014.

17 Portal Rasmi Fatwa Malaysia, http://www.e-fatwa.gov.my/fatwanegeri/hukum-memberi-zakat-kepada-orang-bukan-islam-bagitujuan-dakwah, diakses pada 29 April 2014.
} 
diharuskan memberi zakat kepada orang bukan Islam berdasarkan siasah dan keperluan secara hikmah bagi tujuan dakwah.

Berdasarkan pengalaman negeri Kelantan, program dakwah kepada orang bukan Islam khususnya dakwah kepada orang asli dilaksanakan oleh Unit Dakwah, Majlis Agama Islam Kelantan dengan menggunakan peruntukan wang zakat. Walau bagaimanapun sehingga sekarang tiada fatwa khusus yang memperincikan takrifan asnaf al-mu'allafatu qulūbuhum, sama ada ia meliputi orang Islam sahaja atau merangkumi orang kafir.

\section{MAJLIS AGAMA ISLAM JOHOR (MAIJ) SEBAGAI PENGURUS ZAKAT DI NEGERI JOHOR}

Majlis Agama Islam Negeri Johor (MAIJ), ditubuhkan pada tahun 1925 di bawah kuatkuasa Bahagian IV, Bab XV, Lembaga Aturan Bagi Pemerintahan Raja, iaitu satu peraturan khusus untuk istana dan adat istiadat raja. Nama ini bukanlah seperti yang biasa disebut Majlis Agama dan Adat Istiadat Melayu. Bahagian IV fasal XV, menerangkan tugas MAIJ iaitu: "Timbangkan hal-hal berkenaan dengan kerja agama dan melihatkan yang dilakukan dengan munasabah dalam hal yang kena mengena dengan istiadat yang terharus serta pula menimbangkan hal-hal berkenaan dengan pelajaran agama atas kerabat-kerabat Yang Maha Mulia dan Istana dan lagi melihat makam-makam, sedekah dan lainlain khairat". Oleh kerana matlamat MAIJ pada awalnya untuk kepentingan istana, tugas Mufti dan Kadi Besar mulai tahun 1925 juga ditentukan bagi maksud tersebut.

\section{Bidang Kuasa Majlis Agama Islam Johor (MAIJ)}

Dua fungsi utama MAIJ adalah sebagai penggubal dasar agama Islam dan sebagai penyelaras agensi dalam Jabatan Agama, seperti menyelesaikan masalah yang dihadapi oleh Pejabat Mufti dan Pejabat Yang Dipertua. Manakala Jabatan Agama Johor sebagai badan yang melaksana keputusan MAIJ.

Bidang kuasa ini adalah mengikut sebagaimana Bahagian II, Seksyen 4 hingga 13, Enakmen Pentadbiran Agama Islam Bilangan 14 Tahun 1978. Selepas itu, Enakmen Pentadbiran 
Agama Islam Bilangan 14 Tahun 1978 dipinda dan digantikan dengan Enakmen Pentadbiran Agama Islam (Negeri Johor) 2003. Hal ini merujuk Seksyen 4(1) Pentadbiran Agama Islam (Negeri Johor) 2003 menyatakan: "Maka hendaklah ada satu badan bernama 'Majlis Agama Islam Negeri Johor' untuk membantu dan menasihati Sultan dalam perkara- perkara yang berhubungan dengan agama Islam".

Dengan kuatkuasa Bahagian VI Enakmen Pentadbiran Agama Islam (Negeri Johor) 2003 itu, Baitulmal, Zakat \& Fitrah dan Wakaf telah diletakkan secara khusus di bawah pentadbiran MAIJ. ${ }^{18}$

\section{PELAKSANAAN PROGRAM PEMBANGUNAN ASNAF MUALAF}

Agihan zakat untuk golongan mualaf di Malaysia tidak sukar difikirkan. ${ }^{19}$ Pertamanya kerana kerajaan sendiri, melalui pihak penguasa agama negeri telah menguruskan soal pungutan dan agihan zakat ini dengan teratur. Keduanya, kerana orang yang paling memerlukannya senang dikenal pasti, iaitulah mereka yang baru memeluk Islam dan memerlukan sumbangan seperti itu. Bilangan mereka banyak sekali dan keperluan mereka lebih daripada sumber yang ada.

Apabila kita menelusuri sejarah pengagihan zakat pada zaman Rasulullah SAW, didapati bahawa pelaksanaan agihan berlaku sama ada kepada orang-orang yang belum memeluk Islam dan diharapkan dengan pemberian itu mereka akan memeluk Islam, juga diagihkan kepada orang-orang yang baru memeluk Islam agar kukuh pegangan mereka terhadap Islam. Dalam konteks amalan yang dilaksanakan oleh pihak Majlis Agama Islam Negerinegeri (MAIN), didapati sebahagian besar dana zakat dikhususkan kepada mereka yang baru memeluk agama Islam sebagaimana

\footnotetext{
Laporan Eksklusif MAIJ 2010

19 Mahmood Zuhdi Abdul Majid, Pengurusan Zakat (Kuala Lumpur:

Dewan Bahasa dan Pustaka, 2003), 444.
} 
yang termaktub di dalam Enakmen Pentadbiran Agama Islam Negeri-negeri berkenaan. ${ }^{20}$

Di Malaysia amnya dan Negeri Johor khususnya, program pembangunan asnaf mualaf yang disusun oleh Majlis Agama Islam Johor (MAIJ) adalah bertepatan dengan kehendak fiqh dan syarak. Bukan itu sahaja, bahkan peruntukan yang dikhususkan untuk asnaf ini setiap tahun adalah peruntukan yang besar sebagaimana yang ditunjukkan pada jadual di bawah:

\section{STATISTIK AGIHAN ZAKAT MENGIKUT ASNAF BAGI TAHUN 2007-2011}

\begin{tabular}{|c|c|c|c|c|c|}
\hline 至 & $\begin{array}{r}2007 \\
(\mathrm{RM})\end{array}$ & $\begin{array}{l}2008 \\
(\mathrm{RM})\end{array}$ & $\begin{array}{l}2009 \\
(\mathrm{RM})\end{array}$ & $\begin{array}{l}2010 \\
(R M)\end{array}$ & $\begin{array}{c}2011 \\
(\mathrm{RM})\end{array}$ \\
\hline 章 & $5,169,931.01$ & $6,913,072.00$ & $9,896,091.37$ & $13,402,328.92$ & $14,891,099.00$ \\
\hline$\frac{. \Xi}{\sum^{\Xi}}$ & $14,533,646.71$ & $17,926,266.19$ & $22,885,290.05$ & $29,404,652.03$ & $34,913,964.36$ \\
\hline 离 & $10,477,016.78$ & $11,918,083.47$ & $11,084,748.35$ & $13,561,051.51$ & $15,676,137.67$ \\
\hline 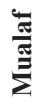 & $\begin{array}{c}4,553,107.76 \\
(7 \%)\end{array}$ & $\begin{array}{c}6,186,416.72 \\
(8 \%)\end{array}$ & $\begin{array}{c}8,772,522.51 \\
(7 \%)\end{array}$ & $\begin{array}{c}8,098,428.14 \\
(6 \%)\end{array}$ & $\begin{array}{c}9,222,345.21 \\
(6 \%)\end{array}$ \\
\hline 急 & $501,591.50$ & $1,794,993.43$ & $2,090,175.02$ & $2,623,277.94$ & $3,983,001.53$ \\
\hline 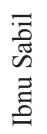 & $47,499.00$ & $133,065.50$ & $192,648.70$ & $153,151.70$ & $131,214,97$ \\
\hline
\end{tabular}

20 Ab. Rahim Ibrahim, "Konsep al-Mualaf \& Agihan Zakat Dalam Konteks Malaysia: Satu Pengenalan”, Kertas Kerja di Bengkel IKaZ Bersama Industri ke-6 di Kuala Lumpur, 2010. 
Pengurusan Zakat Asnaf Muallaf di Negeri Johor:

Satu Sorotan

\begin{tabular}{|c|c|c|c|c|c|}
\hline 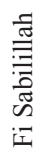 & $29,539,327.23$ & $33,755,743.94$ & $41,446,667.19$ & $47,809,382.71$ & $72,609,715.39$ \\
\hline 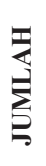 & 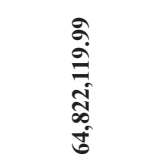 & 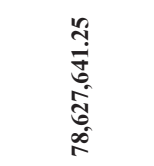 & 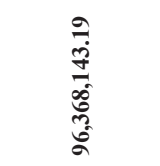 & 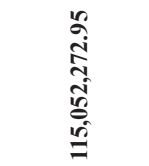 & $\begin{array}{l}m \\
m \\
\infty \\
\stackrel{0}{a} \\
\stackrel{a}{a} \\
\stackrel{5}{a}\end{array}$ \\
\hline
\end{tabular}

Sumber: Majlis Agama Islam Johor (Bahagian Zakat)

Peratusan yang besar menunjukkan keprihatinan yang serius untuk menjaga kebajikan asnaf ini. Pelbagai program yang disusun dengan pelbagai objektif dan sasaran yang tertentu bagi menjamin kekuatan pegangan para mualaf terhadap Islam.

\section{STATISTIK MUALAF DI NEGERI JOHOR}

Statistik Pengislaman Saudara Baru di Negeri Johor (2000-2011) ${ }^{21}$

\begin{tabular}{|c|c|c|c|c|c|c|c|c|c|c|c|c|c|c|}
\hline 电 & Daerah & : & 亏ั่ & ฮั. & 气̊̊̆ & ఫ્త్ & ֻٌ & ڤ્̀ & 亏ิ & 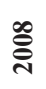 & ஓ्षे & 을 & 국 & $\frac{\bar{E}}{\mathrm{E}}$ \\
\hline 1 & $\begin{array}{l}\text { Johor } \\
\text { Bahru }\end{array}$ & in & $\stackrel{\infty}{+}$ & کु & $\stackrel{n}{q}$ & ๙ू & 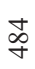 & $\bar{q}$ & $\stackrel{\infty}{\infty}$ & $\stackrel{\nabla}{n}$ & $\stackrel{\infty}{n}$ & $\bar{\sigma}$ & $\stackrel{\mathscr{\vartheta}}{\vartheta}$ & $\underset{\text { in }}{\stackrel{F}{*}}$ \\
\hline 2 & Muar & లి & $\stackrel{\infty}{\sim}$ & i & $\hat{n}$ & ले & m & กิ & $\hat{n}$ & กี & $\hat{n}$ & $\bar{m}$ & $\stackrel{\sim}{\sim}$ & $\frac{R}{m}$ \\
\hline 3 & $\begin{array}{l}\text { Batu } \\
\text { Pahat }\end{array}$ & $\stackrel{\infty}{\sim}$ & 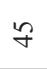 & in & $\overrightarrow{6}$ & in & 6 & $\hat{\sim}$ & $\vec{n}$ & ले & ก & $\stackrel{R}{r}$ & $\mathscr{\vartheta}$ & 占 \\
\hline 4 & Kluang & 운 & $m$ & $n$ & $M$ & $\widehat{6}$ & 戸 & $\nabla$ & 寸 & ஜ & 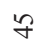 & $\mathbb{N}$ & f & है \\
\hline 5 & Segamat & $\vec{\sim}$ & 9 & ஓ & $\Xi$ & $\stackrel{ \pm}{\sim}$ & 9 & $\stackrel{2}{2}$ & શે & নे & $\hat{\sim}$ & $\vec{m}$ & $\infty$ & $\stackrel{\text { i }}{\stackrel{1}{2}}$ \\
\hline 6 & Pontian & ㄱ & 2 & 2 & ㄱ & iิ & $\stackrel{\infty}{\sim}$ & $\stackrel{\sim}{\sim}$ & $\overparen{\curvearrowright}$ & 2 & $\stackrel{\sim}{\sim}$ & 오 & จิ & ?ֶ. \\
\hline 7 & $\begin{array}{l}\text { Kota } \\
\text { Tinggi }\end{array}$ & in & i & in & $\infty$ & in & 戸 & in & $\stackrel{\infty}{+}$ & 导 & $\dot{n}$ & $\infty$ & $\ddot{n}$ & $\widehat{\widehat{\sigma}}$ \\
\hline 8 & Mersing & 으 & 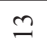 & $\infty$ & $=$ & $\infty$ & $a$ & $=$ & I & $\stackrel{0}{=}$ & I & $\infty$ & $n$ & $\stackrel{?}{ \pm}$ \\
\hline 9 & $\begin{array}{l}\text { Kulai } \\
\text { Jaya* }\end{array}$ & & & & & & & & & & - & $n$ & $m$ & 8 \\
\hline
\end{tabular}

21 Maklumat rasmi daripada Unit Ukhuwwah, Jabatan Agama Johor. 


\begin{tabular}{|c|c|c|c|c|c|c|c|c|c|c|c|c|c|c|}
\hline 10 & Ledang* & & & & & & & & & & 0 & $\infty$ & $\nabla$ & $\simeq$ \\
\hline & 蛋 & in & in & $\stackrel{2}{2}$ & in & : & $\overline{\mathrm{N}}$ & กี & $\frac{\pi}{\infty}$ & 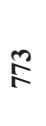 & f & క్రి & है: & $\stackrel{\hat{\infty}}{\hat{\infty}}$ \\
\hline
\end{tabular}

* Daerah Kulai Jaya dan Ledang merupakan dua daerah baru yang diisytiharkan pada tahun 2009, sebelum itu kedua-duanya merupakan daerah kecil.

\section{UNIT UKHUWAH}

\section{Unit Ukhuwah, Bahagian Dakwah Jabatan Agama Johor}

Bagi negeri Johor, pihak MAIJ telah menyerahkan tanggungjawab bagi menguruskan hak-hak mualaf kepada Unit Ukhuwah, Bahagian Dakwah, Jabatan Agama Johor (JAJ). Pihak MAIJ berperanan sebagai pengutip dan pengagih zakat dan melalui Program Pembangunan Asnaf Mualaf, sejumlah besar peruntukan dikhaskan setiap tahun bagi menjayakan program ini yang dikendalikan oleh Unit Ukhuwah. Bagi tahun 2007, sebanyak RM 4,553,107.76 diperuntukkan dan meningkat kepada RM 6,186,416.72 untuk tahun 2008, manakala bagi tahun 2009, sejumlah RM 8,772,522.51 dikhususkan bagi kegunaan asnaf mualaf. Walau bagaimanapun, berlaku sedikit penurunan pada tahun 2010 iaitu RM 8,098,428.14, penurunan sebanyak RM $674,094.37$.

Unit Ukhuwah sebelum ini dikenali dengan Bahagian Kebajikan Saudara Baru. Ia telah ditubuhkan pada tahun 1974 dengan dikelolakan oleh seorang Pegawai Agama (Pengelola Kebajikan Saudara Baru Negeri Johor) dibantu oleh seorang Pembantu Pengelola Kebajikan Saudara Baru (Peringkat Ibu Pejabat). Manakala di daerah-daerah pula dibantu oleh Penolong Pengelola Kebajikan Saudara Baru Daerah yang juga Pegawai Penerangan Agama Daerah. Keadaan ini berjalan hingga pertengahan tahun 1981.

Pada awal bulan Ogos 1981 diadakan perubahan dengan melantik Pegawai Kebajikan Saudara Baru Negeri Johor yang 
terdiri daripada Pegawai-pegawai Penerangan Agama Daerah (merangkap) mulai dari 1 Ogos 1981 dan berlanjutan hingga tahun 1984. Pada bulan Jun 1984, Pegawai Kebajikan Saudara Baru Negeri Johor seramai 9 orang telah dilantik di mana 8 orang ditempatkan di tiap-tiap daerah dan seorang di ibu pejabat. Pada tahun 1986 seorang pembantu tadbir telah dilantik bagi membuat kerja-kerja Bahagian Kebajikan Saudara Baru.

\section{PROGRAM-PROGRAM UNIT UKHUWAH ${ }^{22}$}

Program Pembangunan Asnaf Mualaf yang telah disusun oleh MAIJ dengan kerjasama Unit Ukhuwah telah disusun dan dirangka dengan teliti mengikut keperluan dan kehendak asnaf mualaf. Di antara program yang disusun adalah sebagaimana berikut:

a) Kursus-kursus Bersiri seperti Pemantapan Akidah Saudara Kita, Kursus Pengurusan Jenazah dan Kursus Penyembelihan.

b) Pengislaman Beramai-ramai, Pernikahan beramai-ramai, Program Keluarga Mawaddah dan Kem Anak Soleh.

c) Majlis Iftar Ramadan, Sambutan Hari Raya (Aidilfitri dan Aidil Adha) dan Hari Silaturrahim.

d) Sambutan Maal Hijrah dan Pemilihan Tokoh Saudara Kita.

Apabila melihat kepada program-program yang disusun, secara umum ianya boleh dibahagikan kepada beberapa kategori, iaitu program bagi meraikan keIslaman mereka, program bagi meningkatkan kefahaman mereka berkaitan fardu ain, program hari-hari kebesaran Islam dan program galakan saudara kita.

Di samping ibu pejabat Unit Ukhuwwah di Johor Bahru, ia juga mempunyai cawangan di setiap daerah. Ianya diketuai oleh seorang pengerusi. Setiap daerah mempunyai pengalaman dan cabaran masing-masing.

22 Unit Ukhuwwah, Bahagian Dakwah, Jabatan Agama Johor. 


\section{PERMASALAHAN DALAM PENGURUSAN MUALAF DI JOHOR $^{23}$}

\section{Aspek Memeluk Islam}

1.1 Memeluk Islam tanpa pengetahuan keluarga. Apabila berlakunya kematian akan mengakibatkan berebut jenazah dan harta.

1.2 Memeluk Islam tanpa mengisytiharkan status pernikahan terlebih dahulu (sebelum Islam). Lebih malang jika saudara kita yang memeluk Islam kerana ingin berkahwin dengan orang Islam dan dalam masa yang sama mempunyai isteri yang bukan Islam. Antara tanda-tanda kes ini ialah selepas memeluk Islam, mualaf ini enggan menukar nama di dalam kad pengenalan. Antara sebabnya ialah kerana mualaf ini ingin menyembunyikan status dari isterinya yang bukan Islam.

1.3 Bagi mereka yang memeluk Islam di bawah 18 tahun hendaklah mendapatkan kebenaran ibu bapa (bersurat dan akuan bersumpah ibu bapa bukan Islam). Timbul isu apabila di bawah umur ingin memeluk Islam dan bimbang jika mereka mati dalam keadaan kufur.

\section{Aspek Pengajian dan Bimbingan Saudara Kita}

2.1 Saudara kita yang memeluk Islam dibekalkan pamplet jadual kelas di atas selepas memeluk Islam. Unit Ukhuwah menyediakan kelas dan guru yang berupaya membimbing mereka untuk mendalami Islam.

2.3 Walau bagaimanapun, sebilangan kecil daripada mereka yang memeluk Islam tidak hadir ke kelas kerana faktor masa, bekerja dan komitmen pada keluarga. Sebahagian daripada mereka memeluk Islam kerana ingin berkahwin. Apabila telah mendirikan rumahtangga mereka tidak lagi

23 Unit Ukhuwwah, Bahagian Dakwah, Jabatan Agama Johor. 
datang ke kelas. Perkara ini adalah antara masalah yang sering berlaku. Lebih malang lagi jika pasangannya yang merupakan muslim asal gagal memberikan panduan dan bimbingan untuk menjadi seorang muslim yang baik.

2.4 Bagi mereka yang menghadiri kelas akan diberikan wang tambang untuk menghadiri kelas. Unit Ukhuwah sedang menyediakan satu garis panduan bagi mereka yang menghadiri kelas agar diberikan elaun bagi setiap kenaikan tahap pembelajaran.

\section{Tempoh Pemberian Bantuan Kepada Mualaf}

Bilakah waktunya saudara baru harus berdikari untuk memastikan potensi dalam kehidupan sebagai pemeluk Islam yang baru terus berkembang tanpa perlu lagi sokongan sesiapa, khususnya bahagian mualaf? ${ }^{24}$

MAIJ adalah pihak berkuasa yang mendaftar pengislaman, memberi bimbingan dan menentukan hak asnaf zakat ke atas saudara kita atau mualaf. Ukuran "mualaf" disukat sehingga mereka memiliki iman yang mantap dan tanpa mengharap lagi agihan asnaf yang diperuntukkan. Oleh itu, selagi belum tercapai tahap iman yang mantap, hak asnafnya masih perlu ditunaikan menurut para ulama. Perkara ini juga disebutkan oleh Penolong Pengarah Unit Ukhuwwah, Jabatan Agama Johor yang menyatakan bahawa di negeri Johor, belum ada tempoh yang ditetapkan untuk gelaran mualaf dan tempoh pemberian bantuan kepada mereka.

Antara perkara yang perlu diberikan perhatian ialah sejauhmana keberkesanan program pembangunan asnaf mualaf mencapai objektif dan matlamatnya. Sememangnya diakui bahawa MAIJ telah banyak membantu mualaf selama ini. Namun rata-rata mualaf masih belum boleh dianggap mampu berdikari selagi keimanan mereka belum mantap.

24 Buletin Majlis Agama Islam Johor (MAIJ), bil. 51, 2013, 34. 


\section{Bentuk Bantuan Kepada Asnaf Mualaf Di Negeri Johor}

Bagi asnaf mualaf di negeri Johor, bentuk bantuan tahunan yang diperuntukkan adalah untuk kegunaan berikut:

\begin{tabular}{|c|c|c|}
\hline $\bar{\theta}$ & Jenis Bantuan & Catatan \\
\hline 1 & Gaji dan elaun kakitangan Unit Ukhuwwah & $\begin{array}{l}\text { Mengikut } \\
\text { keperluan }\end{array}$ \\
\hline 2 & Perbelanjaan pengurusan pejabat & $\begin{array}{l}\text { Mengikut } \\
\text { keperluan }\end{array}$ \\
\hline 3 & Saguhati tenaga pengajar & $\begin{array}{l}\text { Mengikut } \\
\text { keperluan }\end{array}$ \\
\hline 4 & $\begin{array}{l}\text { Program-program dakwah } \\
\text { - Lawatan ke Perkampungan Orang } \\
\text { Asli. } \\
\text { - Pembinaan Kompleks Agama di } \\
\quad \text { Perkampungan Orang Asli } \\
\end{array}$ & $\begin{array}{l}\text { Mengikut } \\
\text { keperluan }\end{array}$ \\
\hline 5 & $\begin{array}{l}\text { Kursus dan latihan saudara baru } \\
\text { - Kelas bimbingan Fardhu Ain } \\
\text { - Kursus Kempimpinan Ketua } \\
\text { - Kasyarakat } \\
\text { - Kursus kecemerlangan sahsiah }\end{array}$ & $\begin{array}{l}\text { Mengikut } \\
\text { keperluan }\end{array}$ \\
\hline 6 & Insurans berkelompok kakitangan & $\begin{array}{l}\text { Mengikut } \\
\text { keperluan }\end{array}$ \\
\hline 7 & $\begin{array}{l}\text { Skim-skim bantuan Mualaf } \\
\text { - Skim bantuan sara hidup bulanan } \\
\text { - Bantuan pelajaran } \\
\text { - Bantuan semasa } \\
\text { - Bantuan hari raya } \\
\text { - Bantuan perubatan } \\
\text { - } \text { Kerajaan kepada Badan Bukan } \\
\text { Bantuan membaiki rumah } \\
\end{array}$ & $\begin{array}{l}\text { Mengikut } \\
\text { keperluan }\end{array}$ \\
\hline
\end{tabular}

Jadual di atas menunjukkan program-program yang telah disusun atur oleh Unit Ukhuwwah bagi menjinakkan hati ( $t a$ 'lif $a l-q u l \bar{u} b$ ) para mualaf di negeri Johor. Secara umumnya, programprogram yang disusun boleh dibahagikan kepada dua bahagian 
iaitu dalaman dan luaran. Program-program dalaman adalah terdiri daripada:

Kelas-kelas pengajian fardu ain, pengajian akidah, akhlak, alQuran dan lain-lain lagi. Program-program ini disusun bagi memastikan para mualaf mendapat kefahaman dan pendidikan yang mencukupi untuk menjadi seorang muslim yang baik dan dapat beramal dengan amalan-amalan Islam.

a. Program peningkatan kualiti staf.

Bagi memastikan kakitangan Unit Ukhuwwah adalah terlatih, maka program-program peningkatan kualiti perkhidmatan seperti kursus-kursus dan latihan turut diadakan.

Bagi melengkapkan diri tenaga pengajar dan pembimbing saudara baru di Negeri Johor, Kursus Metodologi Dakwah di Kalangan Masyarakat Muslim Orang Asli telah dianjurkan oleh Bahagian Dakwah, Jabatan Agama Johor. Antara objektif program ini ialah bagi memberikan motivasi dan dorongan kepada tenaga pengajar yang datang dari seluruh daerah negeri Johor. Melalui kursus ini, para peserta didedahkan dengan pelbagai teknik penyampaian yang dikehendaki dalam Islam iaitu dengan hikmah dan kebijaksanaan. ${ }^{25}$

Bagi program luaran pula, merujuk kepada jadual di atas, banyak program yang telah disusun atur bagi memastikan muallaf mendapat perhatian yang sewajarnya dalam Islam. Unit Ukhuwwah melalui tanggungjawab dan amanah yang telah diberikan oleh MAIJ telah merangka pelbagai program dan aktiviti luaran sebagai sokongan dan galakan kepada mualaf agar mereka akan sentiasa dipantau dan menyokong segala usaha bagi meningkatkan tahap kefahaman mereka terhadap Islam. Ianya juga adalah satu medium pendedahan kepada masyarakat tentang peranan dan tugas yang perlu dilaksanakan oleh Unit Ukhuwwah, sekaligus menepis tanggapan kurang baik terhadap pengurusan mualaf.

Tambahan lagi, program-program yang disusun juga diharap dapat menarik golongan yang bukan Islam untuk memeluk

25 Buletin Majis Agama Islam Johor, Keluaran Khas 2007, bil. 5 Tahun ke-8, 1428H/2007M. 
Islam kerana melihat keindahan Islam. Ianya juga bertepatan dengan konsep ta'lîf al-qulüb yang telah dibincangkan di awal kajian ini.

\section{RUMUSAN DAN CADANGAN}

\section{Cadangan Penambahbaikan:}

\section{Menaik Taraf Unit Ukhuwwah Kepada Satu Bahagian (Divisyen).}

Bagi memperkasa peranan dan fungsi Unit Ukhuwah, ia perlu dinaiktaraf sebagai sebuah bahagian yang diketuai oleh seorang Ketua Penolong Pengarah, penambahan staf bagi unit yang kritikal adalah sangat penting bagi menjamin kebajikan dan hak-hak mualaf di negeri Johor dan daerah Johor Bahru. Dengan meningkatnya jumlah mereka yang memeluk Islam setiap tahun, tadbir urus yang baik akan memastikan perkara ini dapat berterusan. Sememangnya menjadi satu kebanggaan apabila melihat kuantiti yang memeluk Islam semakin bertambah setiap tahun, namun adalah malang juga sekiranya ramai juga dalam kalangan mereka yang memohon untuk keluar daripada Islam kerana kegagalan kita menjinakkan hati (ta'līf al-qulüb) mereka untuk terus bersama Islam.

\section{Pusat Pengajian Training of Trainers (TOT).}

Dakwah kepada mualaf adalah aspek yang sangat penting bagi merealisasikan konsep ta' lïf. Meskipun begitu, para pembimbing dan pendakwah perlu kepada latihan dan bimbingan selaku tenaga pengajar. Ianya perlu dipelajari supaya dapat menghasilkan output yang berkesan. Justeru, pihak MAIJ dicadangkan agar menyusun program/bengkel/kursus sama ada jangka panjang atau pendek, secara sekaligus (one-off) atau bersiri bagi melatih para pendakwah yang terdiri sama ada daripada para $d \bar{a}{ }^{\prime} \hat{\imath}$ dari kalangan asātizah yang sedia ada atau daripada golongan mualaf sendiri. Para mualaf sendiri boleh dijemput sebagai model kepada permasalahan mualaf dan cadangan daripada mereka juga boleh diambil kira. 
Di Malaysia, terdapat beberapa pusat latihan yang ditubuhkan bagi membantu program ini dilaksanakan. Antara yang boleh disebutkan di sini ialah Institut Dakwah Islamiah Perkim (IDIP ${ }^{26}$ dan Pusat Bimbingan Islam Sultan Abdul Halim Mu'adzam Shah (PUSBA). ${ }^{27}$

Objektif kelas tersebut ialah memberi pendedahan, penjelasan dan bimbingan lanjutan tentang perkara-perkara fardhu ain dan fardhu kifayah serta meningkatkan kefahaman, penghayatan dan pengamalan ajaran Islam dengan menitikberatkan kepada nilai ilmu bagi melahirkan Muslim yang beriman dan bertakwa di samping mengukuhkan akidah saudara kita agar lebih teratur dan terancang dalam menghadapi cabaran yang mendatang. ${ }^{28}$

Satu aspek yang sangat penting dipelajari oleh para pendakwah ialah mempelajari perbandingan agama. Menurut pengasas Hidayah Centre Jemaah Islam Malaysia (ISLAH), Muhammad Abdullah Nicholas Sylvester, beliau mencadangkan bahawa para pegawai pembimbing, guru-guru dan para pendakwah perlu mempelajari dan mendalami agama lain bagi memudahkan mereka untuk berhujah dengan masyarakat pelbagai bangsa di negara ini. Pendekatan dialog antara agama adalah salah satu pendekatan yang efektif dan memberi fokus kepada matlamat memahami antara satu sama lain.

Kesimpulannya, adalah menjadi harapan daripada seluruh masyarakat negeri Johor amnya dan para mualaf khasnya untuk mempunyai sebuah pusat latihan saudara kita sendiri di Negeri Johor.

26 Institut Dakwah Islamiah Perkim (IDIP), http://idip.edu.my/, diakses pada 20 April 2014.

27 Pusat Bimbingan Islam Sultan Abdul Halim Mu'adzam Shah (PUSBA), http://www.maik.gov.my/index.php?q=content/pusba, diakses pada 20 April 2014.

28 Laman web rasmi Jabatan Kemajuan Islam Malaysia (JAKIM): http://www.islam.gov.my/en/memperkasa-pendidikan-saudara-kita, diakses pada 20 April 2014. 


\section{Ulul Albab Anak-Anak Mualaf (memperkasa kefahaman mualaf).}

Satu perkara yang mungkin terlepas pandang ialah nasib anak-anak mualaf terutamanya mereka yang berada di kawasan pedalaman. Mereka tidak boleh dipinggirkan. Kebiasaannya mereka adalah golongan yang tercicir dalam pelajaran disebabkan faktor-faktor seperti persekitaran dan kurangnya semangat persaingan.

Oleh itu, satu langkah untuk memperkasa ilmu pengetahuan para mualaf ialah dengan mewujudkan satu program khusus yang boleh dinamakan sebagai Ulul Albab bagi melahirkan golongan mualaf yang berpengetahuan tinggi dalam bidang agama seterusnya dapat membantu mengurangkan masalah kekurangan guru dan pembimbing untuk mualaf.

\section{PENUTUP}

Pengurusan hak golongan mualaf adalah satu perkara yang penting dalam sistem pentadbiran Islam. Pengurusan yang baik pasti akan memastikan golongan ini terus mencintai Islam dan akan menjadi aset penting di dalam perkembangan Islam di Malaysia amnya dan negeri Johor khususnya. Kerjasama daripada semua pihak terutamanya institusi pengurus zakat, pihak berkuasa agama dan seluruh masyarakat amat diperlukan sehingga segala permasalahan dapat diselesaikan dan cadangan penambahbaikan dapat dilaksanakan.

\section{BIBLIOGRAFI}

'Abd Allah Nāṣih Ulwān. Ahkām al-Zakāh 'alā Daw'i alMadhāhib al-Arba 'ah. Qāhirah: Dār al-Salām, 1978.

Ab. Rahim Ibrahim. "Konsep al-Mualaf \& Agihan Zakat Dalam Konteks Malaysia: Satu Pengenalan”. Kertas Kerja di Bengkel IKaZ Bersama Industri ke-6 di Kuala Lumpur, 2010 .

Al-Kāsānī, 'Alā' al-Dīn Abū Bakar. Badā'i ' al-Ṣanā' 'i'. Bayrūt: Dār al-Kutub al-'Ilmiyyah, 2003. 
Al-Kharsyī, Abū 'Abd Allāh Muḥammad. Syarh al-Kharsȳ̄ 'alā al-Mukhtaṣar al-Jalīl. Mesir: Bulāq, 1317.

Al-Maqdisī, Bahā' al-Dīn 'Abd al-Raḥmān bin Ibrāhim. Al- 'Uddah Syarh al- 'Umdah. Qāhirah: Maktabah al-Qurān,1996.

Al-'Ānī, Khālid 'Abd Razzāq. Mașārif al-Zakāt wa Tamlīkuhā fì Daw'ì al-kitāb wa al-Sunnah. 'Ammān: Dār Usāmah li alNasyr wa al-Tawzī’, 1999.

Al-Qaradaghi-laman web Prof. Dr. Muhyiddin al-Qaradaghi www.qaradaghi.com - Masrif al-Muallafatu Qulübuhum wa Taṭbīqātuhu al-Mu'āṣirah.

Al-Qurțubī, Abū 'Umar al-Namrī. Al-Jāmi ' li-Ahkām al-Qur'ān. Qāhirah: Dār al-Ḥadīth, 2002.

Al-Qurțub̄i, Abū 'Abd Allāh Muḥammad bin Aḥmad al-Anșārī. Al-Jāmi ' li Ahkām al-Qur'ān. Riyāḍ: Maṭba'ah Dār 'Ālam li al-Kutub li al-Ṭibā'ah wa al-Nasyr wa al-Tawzì’, 2003.

Al-Syafi 'ī, Muḥammad Bin Idrīs. Al-Umm. Al-Manșūrah: Mesir, Dār al-Wafā', 2001.

Al-Ṭabarī, Abū Ja'far Muhammad Ibn Jarīr. Al-Tafsīr al-Tabarī. Bayrūt: Dār al-Kutub al-'Ilmiyyah, 1997.

Al-Zuḥaylī, Wahbah. Al-Fiqh al-Islāmī wa Adillatuhu. Bayrūt: Dār al-Fikr, 2004.

Buletin Majis Agama Islam Johor. Keluaran Khas 2007. Bil. 5, Tahun ke-8 1428H/2007M.

Buletin Majlis Agama Islam Johor (MAIJ). Bil. 51, 2013, 34.

Enakmen Pentadbiran Agama Islam (Negeri Johor) 2003.

Hasanah Abd Khafidz. "Asnaf Lapan: Kesan Nilai Semasa dan Setempat dalam Menentukan Pentafsirannya di Malaysia". Thesis (Ph.D.), Jabatan Fiqh dan Usul, Akademi Pengajian Islam, Universiti Malaya, 2006.

Institut Dakwah Islamiah Perkim (IDIP). http://idip.edu.my/. Diakses pada 20 April 2014. 
Jabatan Kemajuan Islam Malaysia (JAKIM). http://www.islam. gov.my/en/memperkasa-pendidikan-saudara-kita. Diakses pada 20 April 2014.

Jabatan Mufti Selangor. http://www.muftiselangor.gov.my/ $\mathrm{ms} /$ fatwa-tahunan/pewartaan/2010-terkini/311-hukummenggunakan-peruntukan-asnaf-mualaf-untuk-programdan-hal-ehwal-yang-berkaitan-dengan-aktiviti-dakwahkepada-bukan-Islam.

Noresah Baharom. Kamus Dewan Edisi Keempat. Dewan Bahasa dan Pustaka, Kuala Lumpur 2007.

Mahmood Zuhdi Hj. Abdul Majid. Pengurusan Zakat. Kuala Lumpur: Dewan Bahasa dan Pustaka, 2003.

Majlis Agama Islam Johor (2010), Laporan Eksklusif MAIJ 2010.

Portal Rasmi Fatwa Malaysia. http://www.e-fatwa.gov.my/fatwanegeri/hukum-memberi-zakat-kepada-orang-bukan-islambagi-tujuan-dakwah. Diakses pada 29 April 2014.

Pusat Bimbingan Islam Sultan Abdul Halim Mu'adzam Shah (PUSBA). http://www.maik.gov.my/index.php?q=content/ pusba. Diakses pada 20 April 2014.

Syams al-Dīn al-Syaykh Muḥammad Arafah al-Dusuqī. Hāsyiah al-Dusuqī Ñalé-al-Syarḥ al-Kabir . Qāhirah: Dār Ihyyā' alKutub al-‘Arabiah Isā al-Bābi al-Ḥalabī, t.t. 495.

Temubual dengan Ustazah Maimunah bt. Othman, Penolong Pengarah (Ketua) Unit Ukhuwwah, Bahagian Dakwah JAJ, 5.1.2014.

TheAbsolute Reality. http://www.quran4u.com/Tafsiraya/009\%20 Tawbah.htm\#لص. Diakses pada 21 April 2014.

The Islamic Computing Centre, London, http://www.islam101. com/quran/quranPickthal/trans-pickthal.text. Diakses pada 21 April 2014. 